\title{
Examining the role of store design on consumers' cross-sectional perceptions of retail brand loyalty
}

John Murray Dr.

Technological University Dublin, john.murray@tudublin.ie

Jonathan Elms

Massey University, j.r.elms@massey.ac.nz

Christoph Teller

University of Surrey, c.teller@surrey.ac.uk

Follow this and additional works at: https://arrow.tudublin.ie/buschrsmart

Part of the Sales and Merchandising Commons

\section{Recommended Citation}

Murray, John \& Elms, Jonathan \& Teller, Christoph. (2017). Examining the role of store design on consumers' cross-sectional perceptions of retail brand loyalty. Journal of Retailing and Consumer Services. 38. 147-156. 10.1016/j.jretconser.2017.06.001.

This Article is brought to you for free and open access by the School of Retail and Services Management at ARROW@TU Dublin. It has been accepted for inclusion in Articles by an authorized administrator of ARROW@TU Dublin. For more information, please contact arrow.admin@tudublin.ie, aisling.coyne@tudublin.ie, gerard.connolly@tudublin.ie.

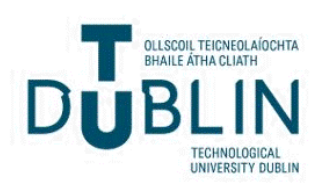




\title{
Examining the role of store design on consumers' cross-sectional perceptions of retail brand loyalty
}

\author{
John Murray ${ }^{\mathrm{a}, *}$, Jonathan Elms ${ }^{\mathrm{b}}$, Christoph Teller ${ }^{\mathrm{c}}$ \\ a School of Retail \& Services Management, College of Business, Dublin Institute of Technology, Aungier Street, Dublin 2, Ireland \\ b Centre for Advanced Retail Studies (CARS), Massey Business School (Albany), Massey University, Private Bag 102904, North Shore, Auckland 0745, New Zealand \\ ${ }^{\mathrm{c}}$ Department of Marketing and Retailing, Surrey Business School, University of Surrey, Guildford, Surrey GU2 7XH, UK
}

\section{A R T I C L E I N F O}

Keywords:
Novelty
Complexity
Design
Structural equations modeling
Price
Retail brand loyalty

Design

Price

Retail brand loyalty

\begin{abstract}
A B S T R A C T
This paper compares new and established store design prototypes of the same retailer to examine the role of consumers' cross-sectional perceptions of retail brand loyalty. In-store surveys were administered to capture consumers' store-level perceptions towards a new store prototype and an older established prototype of the same fast fashion retailer. The data was subjected to multi-group analyzes with structural equations modeling. The findings suggest that store novelty and complexity promote both store design pleasure and retail brand loyalty outcomes. The different store designs do not, however, account for differences in brand loyalty perceptions at the overall retailer level when multi-group comparisons of both store designs are made. Consumers of newer store designs are found to possess a heightened sensitivity to price perceptions. Managerial implications of the effects of store novelty and complexity on retail brand loyalty are also presented.
\end{abstract}

\section{Introduction}

Studies have examined the role of store design in the development of successful store environments (e.g. Sharma and Stafford, 2000; Kumar and Kim, 2014; Oh et al., 2008; Baker et al., 1994; Wakefield and Baker, 1998; Baker Parasuraman et al., 2002; Garaus et al., 2015). Nevertheless, how, and to what extent, consumers' brand preferences are affected by attractive designs remains limited in the extant literature (see, Landwehr et al., 2012; Landwehr et al., 2011). How does, for example, the introduction of novel or more complex store design affect consumers' perceptions of an existing prototype? What degree of novelty and/or complexity does a newly introduced store prototype need to exhibit to affect consumers' perceptions towards an established and familiar prototype? The study presented in this paper addresses such questions, and, to the best of the authors' knowledge, it is the first to compare new and established store prototypes of the same retailer for this particular purpose.

This paper addresses calls for studies of the store environment to progress beyond the employment of singular atmospheric variables, e.g. lighting, color, temperature, music (Eroglu and Machleit, 2008; Teller and Dennis, 2012). It also complements studies that examine the impacts of flagship stores on consumers' retail brand perceptions based on offering novel experiences (e.g. Dolbec and Chetbat, 2013; Kozinets et al., 2002; Joy et al., 2014; Hollenbeck et al., 2008). Accordingly, the aims of this paper are twofold. First, to examine consumers' perceptions of what constitutes novel and complex store design across two prototype generations of the same retailer. Second, to provide an improved managerial understanding of how novel design introductions effect differences in design pleasure and price perceptions. Consequently, this paper contributes to the extant store environments literature by examining, in a multi-group structural equations modeling study, if store design promotes design pleasure and price perception differences that in-turn help account for different perceptions of retail brand loyalty. The findings of this paper could also aid retail managers to better appreciate how and why differences in retail brand loyalty are evident upon the introduction of new prototype design (when prototype designs are the only material change present across the store network), and the extent that loyalty differences can be explained by the design strategies retailers' employ.

The paper's structure is organized as follows. We begin with a review and synthesis of relevant literature in order to provide a theoretical background for the paper. To this end, a conceptual model is proposed whereupon we can examine how different store designs can influence different perceptions of retail brand loyalty across the two prototype designs. This is followed by a brief discussion of the methodology employed in the study. Thereafter, the results of the study are presented, which are then described and discussed with reference to the extant literature. The subsequent managerial implications are then

\footnotetext{
* Corresponding author.

E-mail addresses: john.murray@dit.ie (J. Murray), j.r.elms@massey.ac.nz (J. Elms), c.teller@surrey.ac.uk (C. Teller).
} 
outlined, followed by a discussion of the main limitations of the study, and suggestions for further research.

\section{Theoretical background}

\subsection{Store Novelty, familiarity and store design pleasure}

Store novelty involves the unexpected, the surprising, the new, and unfamiliar (Donovan and Rossiter, 1982), and is described as an underlying measure of originality (Hirschman, 1980) that reflects one of the key aspects of a firm's innovativeness (Pappu and Quester, 2016). Novel designs that are new and original are more appreciated (Snelders and Hekkert, 1999), with improved recall and recognition benefits arising from achieved differentiation (Foster and McLelland, 2015). Thus, consumers are more likely to remember more novel, branded store environments that better communicate differentiated value (Ponsonby-McCabe and Boyle, 2006), and where expectations disconfirmations induce satisfaction with the environment (Oliver, 1980, 2014). Consumers also derive design pleasure from viewing novelty when they can identify, and successfully process, what they see, and when the design is not too dissimilar to what they have previously encountered (Hekkert and Leder, 2008; Biederman and Vessel, 2006; Stocchi et al., 2016).

The current research proposes that consumers' familiarity and knowledge of different store prototype designs of a same retailer gives rise to consumers' future expectations of the kinds of store design that they could encounter. Thus, a disconfirmed expectation (Oliver, 1980, 2014; Oliver and Winer, 1987) is more likely to arise when the consumer, in viewing other stores of the same retailer, appreciates the introduction of novelty in the current instance.

Accordingly, hypothesis number one states that higher levels of consumers' familiarity with other stores of the retailer informs their understanding of what constitutes novel store design for the retailer in question. Consumers who shop across multiple stores of the retailer will be better informed as to what constitutes novel design. Consumers who identify the store design as novel, it is argued in hypothesis number two, generally tend to evidence greater store design pleasure, particularly when perceptual fluency effects allow consumers to reconcile their knowledge of novel to existing designs.

H1:. The more that consumers are familiar with pre-existing designs of the retailer, the more knowledgeable they are about the novel design properties of the new prototype.

H2:. Reconciliations of store novelty introductions to pre-existing knowledge positively affects consumers' store design pleasure.

\subsection{Store Novelty, complexity and design pleasure}

Complexity is described as involving the identification of: larger numbers of independently selected units that suggest greater dissimilarity and less redundancy; design that promotes variation; and design that increases tension, ambiguity, or arousal (Berlyne, 1971). Complexity, and the related dimensions of order, redundancy, and contrast have been variously considered in the extant literature (e.g. Cox and Cox, 2002; Hekkert and van Wieringen, 1990; Mehrabian and Russell, 1974; Donovan and Rossiter, 1982; Garaus et al., 2015). It remains unclear though how these dimensions of complexity perform to determine a consumer's affective response to a set of environmental or product design stimuli (Donovan and Rossiter, 1982; Cox and Cox, 2002).

The current research argues that store complexity is a categorybased evaluative response that supplements piecemeal-based evaluative processes where both modes of processing are contingent upon the matching and mis-matching of information to pre-existing knowledge (Sujan, 1985). In general, more simple, novel designs are preferred for their ability to induce harmony with less information to process (Frith and Nias, 1974). Simpler, novel designs also increase attention, familiarity, and affect (Kumar and Garg, 2010), thus giving rise to design pleasure (Martindale, 1984; Martindale and Moore, 1988). Greater novelty introductions often require consumers to subordinate the competing tensions present in the design's complexity (Berlyne, 1971), and influence consumers' conscious and unconscious responses as they expend cognitive effort to process the complexity contained in the novelty introduction. It is therefore possible for a consumer, in low store novelty introduction contexts, to more easily perceive familiarity towards design stimuli, given their knowledge of pre-existing prototypes, and to also simultaneously perceive the design as less complex.

Accordingly, hypotheses numbers three and four state that consumers will perceive higher levels of store complexity when they are exposed to and perceive new store designs (hypothesis three). Consumers will also evidence greater store design pleasure when the design is simpler and is therefore more easily reconciled (less cognitive effort expended) to their existing expectations of the retailer's approach to design (hypothesis four).

H3:. Store novelty introductions positively affect consumers' store design complexity perceptions

H4:. More simple (less complex) design perceptions positively affect consumers' store design pleasure.

\subsection{Store Novelty, complexity and retail brand loyalty responses}

Two broad dimensions of loyalty (behavioral and attitudinal) emerge in the literature (Dick and Basu, 1994; Day, 1969; Jacoby and Chestnut, 1978). The majority of extant loyalty research focuses on attitudinal loyalty, and tends to include revisit intentions and preparedness to recommend to others in attitudinal measurement (e.g. Duarte et al., 2004; Yi and La, 2004). The distinction between behavioral and attitudinal loyalty closely resembles two of the four phases of Oliver's (1997) loyalty development process. Cognitive and affective loyalty consider the costs, benefits, imagery, and associations that underpin loyalty, whereas conative and action loyalty evidence higherlevel belief, affect, and intentions to repurchase and brand commitments as states of action readiness that involve choosing one offering over another (Oliver, 1997).

Retail brand loyalty, in this research, reflects consumers' brand information and beliefs about the brand that are superior to competitive offerings (Yoo et al., 2000; Yoo and Donthu, 2001; Oliver, 2014). Given that the prototype context has changed, with the introduction of novel design elements, it is possible to compare if the newer prototype generation, as mediated by store design pleasure, can partly account for differences in loyalty perception across the surveyed stores. We argue that because the only element that is significantly different across the retailers' stores is the prototype design, that changes to the stability of these design contextual cues poses potential impacts for consumers who both repeatedly purchase or have affective responses towards the retailer. A change in consumers' design pleasure towards novel design on account of novel design introductions in effect alters the set of contextual cues that consumers' employ that could be positive or negative depending on preferences for the new design. Where purchases are contingent on the presence of recurring contextual cues, the new design may not permit a practicing of the same habitual response each time, for example, if the design is not preferred. However, novel designs that induce greater store design pleasure may also attract additional consumers and enhance loyalty prospects owing to its improved competitive potential compared to alternatives.

It is argued in the current research that store novelty thus secures levels of affective differentiation and loyalty when easily and fluently processed, and encourages favorable brand evaluations and brand knowledge (Littel and Orth, 2013; Lee and Labroo, 2004; Reber et al., 
2004). Confirmations of simpler design perceptions, in circumstances involving store novelty introductions that are easily processed, promote retail brand knowledge, due to the lower requirement to process information, and result in increased awareness and affect (Kumar and Garg, 2010; Martindale, 1984). The successful subordination of the competing tensions present in complexity also permits consumers to control their behavioral responses (Berlyne, 1971). This encourages consumers to become brand loyal, given their likely repetition of patronage with the retailer with store designs that come to mind more easily. Accordingly, hypotheses numbers five and six state that there is a positive, direct association between store novelty and retail brand loyalty, and a mediated effect also exists between these constructs via store design pleasure. Hypothesis number seven also underscores that more simple designs increase the prospects for securing retail brand loyalty.

H5:. Store novelty perceptions positively affect consumers' retail brand loyalty

H6:. Store design pleasure responses to store environments, given novel design introductions, positively affects consumers' retail brand loyalty

H7:. Simpler store design demands fewer cognitive resources to process and positively affects retail brand loyalty

\subsection{Store design pleasure, retail price and retail brand loyalty}

Price perceptions have been variously considered in retail image and branding research (e.g. Jara and Cliquet, 2012; Hansen and Deutscher, 1977; Jinfeng and Zhilong, 2009; Beristain and Zorrilla, 2011; Dodds et al., 1991). Price is considered as an antecedent of brand loyalty and equity with consumers transforming price signals into cognitive structures provided with meaning (Beristain and Zorrilla, 2011). Given the existence and activation of consumers' knowledge of a brand, as evidenced in brand loyalty, it is possible to examine if retail brand loyalty is determined to a more significant extent by retail price perception or store design pleasure. Both perceived aesthetics and price perceptions can be explained using perceptual fluency theory (Littel and Orth, 2013), and priming effects for price perceptions (Herr, 1989).

It is thus argued that it is possible to discern the contribution of store design pleasure to building retail brand loyalty (hypothesis number six) by examining the mediating role of retail price perceptions (hypotheses numbers eight and nine). Novel design could result in higher retail price perceptions among consumers (Baker et al., 2002), and increases the potential risks for the retailer that their designs are, in effect, negatively repositioning consumers' perceptions on their ability to compete on price. This negative business outcome, should it arise, would obviously need to be addressed by the retailer. Correspondingly, strong associations between retail price and retail brand loyalty perceptions would confirm the contribution of price perceptions in retail brand loyalty development, and possibly its stronger contribution compared to that of store design pleasure.

H8:. Store design pleasure responses to store environments, given novel design introductions, positively affects retail price perceptions.

H9:. Lower perceptions of retail prices, positively affects consumers' retail brand loyalty.

The nine hypotheses are illustrated in the conceptual model presented in Fig. 1.

\subsection{Control variables}

We included control variables in the study to consider confounding effects on our model and to account for heterogeneity in our sample. Considering the time-variant character of store remodeling effects, the nature of consumers' visits, and impacts of store traffic are important in store remodeling research (see e.g. Bruggenet al., 2011). Two variables represent key demographic characteristics (age and employment), two control variables examine shopper behavior (retention time (minutes), and visit exposure frequency), one control variable examines consumers' design value, two variables examine product fashionability and quality perceptions, and two control variables examine store approach behaviors. Respondents' age and employment reflect the moderating influence of experience in design interpretation (Bloch, 1995). Consumers who are younger or older may have visited more store designs of the retailer. Similarly, consumers with different financial resources and design values may also respond differently to design based on the centrality of design in their lives (Bloch, 1995; Bloch et al., 2003). Age is treated as a moderator variable for loyalty (Swoboda et al., 2013; Wakefield and Baker, 1998) as information processing theory, in particular, suggests that older consumers are less likely to seek new information and rely instead on more heuristic or schema-based processing (Walsh et al., 2008). Retention time (Van Kenhove et al., 1999) and visit exposure frequency (Cohen and Basu, 1987; Loken and Ward, 1990; Bruggenet al., 2011) consider the influence of in-store situational effects where consumers who spend more time browsing or who visit more frequently may perceive the store differently to consumers who spend less time browsing and who visit less frequently. Consumers who evidence a greater design value or expertise often possess affective loyalty, brand evaluations, and attitude strength (Swoboda et al., 2013; Alba and Hutchinson, 1987). Consumers who possess a greater design value take a greater interest in novel designs, visit the design more frequently, and are typically likely to adjust their loyalty in response to their affective evaluations of design. Despite a number of calls for more research involving expert-novice perceptions (Alba and Hutchinson, 1987; Sujan and Dekleva, 1987; Bloch, 1995; Bloch et al., 2003; Meyers-Levy and Tybout, 1989), few studies have yet to control for these effects. Similarly, consumers who identify the retailers products to be more fashionable, or of higher quality, may also be more loyal to the retailer. Perceived quality reflects a perceived superiority or excellence (Zeithaml, 1988; Reutterer and Teller, 2009; Pan and Zinkhan, 2006) and reflects positive aesthetic perceptions (Holbrook, 1980), and we thus control for these product related issues. Lastly, we investigate if the presence of possible avoidance behaviors has an effect on retail brand loyalty. Avoidance behaviors have previously examined if perceptual self-distances exist in the context of consumers' brand relationship valence, and brand behaviors (e.g. Park et al., 2013; Donovan and Rossiter, 1982; Elliot et al., 2013). We argue that our inclusion of consumers' visits (both time in minutes and frequency) examines familiarity in a leading European fashion retailer, and together with the avoidance control variable, examines if other performance factors (Zentes, Morschett and Schramm-Klein, 2008) assume an influence on brand loyalty in our model. We therefore control for consumers who intend to avoid exploring or returning to the store.

\section{Methodology}

\subsection{Research design}

To investigate the effects on retail brand loyalty, two stores of a leading European fast-fashion retailer, with a store network of over 300 stores across 10 countries, and who had recently decided to move from a mono-prototype to three-prototype strategy, was used. The retailer currently employs the newer prototype design in roughly seven of its stores. This cross-sectional, multiple-group comparison approach is effective in ascertaining perceptive differences, across related contexts (Londono et al., 2016).

Identical in-store customer surveys were administered, at different times and on different days over a three-week period, after a major refit of one of the two stores. The refit incorporated new prototype design elements whilst the second store employed the most prototypical design the retailer employs across its store network. All stores of the given 


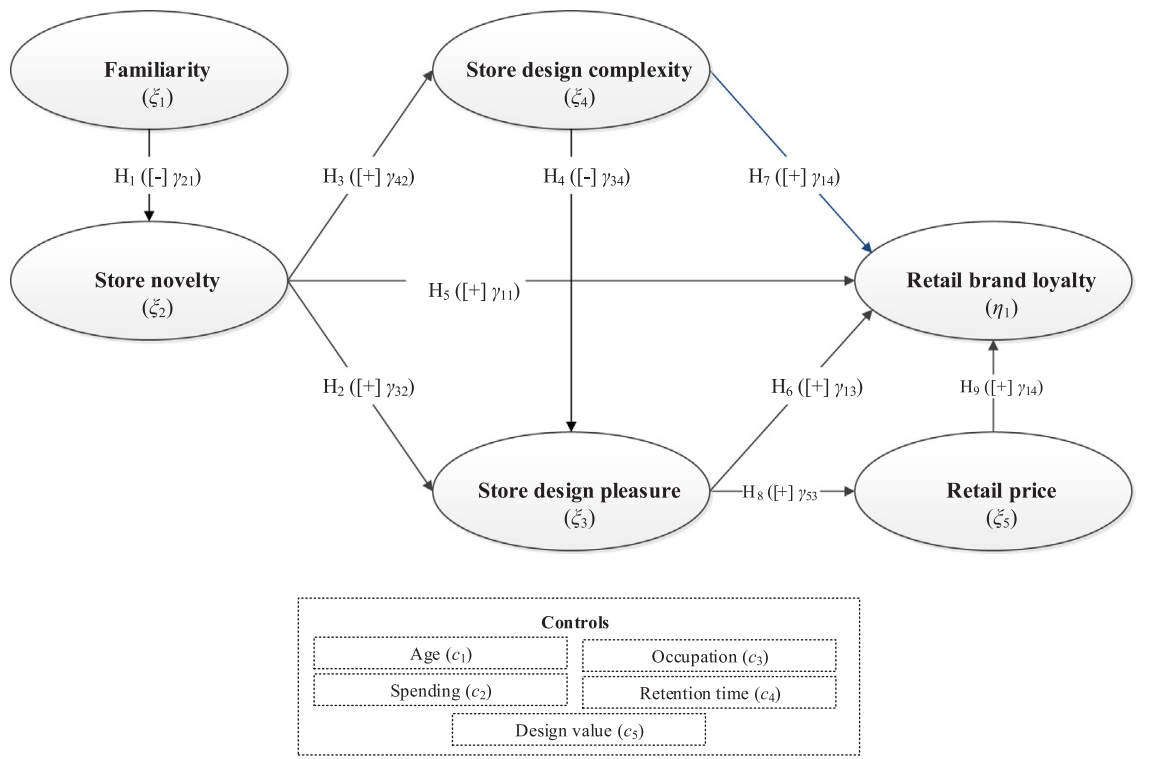

Fig. 1. Conceptual model for examining store design effects on retail brand loyalty.

prototype employ identikit design elements in each location. Both stores were within walking distance of one another, offered the same levels of service, charged the same prices, and served similar target markets.

\subsection{Older and newer designs}

The current cross-sectional research thus examined design effects on retail brand loyalty in a context of newer-design with increased use of strategically placed mannequins, newer materials, and multi-media screens to inspire consumers to choose outfits that are readily available on newer, adjacent fixtures. The newer design also features more prominent directional signage and lighting, thus allowing for easy navigation. Improved building facades, color contrasts, focal points consideration and higher numbers of fitting rooms and cash registers are also employed in the newer prototype (sample images of both stores are shown in Figs. 2 and 3). Consumers' perceptions of these differences across the newer and older prototypes is also supported by the results of the central tendency and $t$-tests available in Appendix A which confirm differences between the newer and older store designs for store novelty, complexity and design pleasure.

\subsection{Sampling plan}

In this research, a strategy involving personally administered questionnaires (conducted in both stores), and a sampling plan involving stratified random sampling, was used. The use of probability sampling procedures is advanced in retail research by Sudman (1980), and is considered in the approach employed in the current research. The primary and representative population identified was 18-35 year old females (this group was also confirmed by the retailer as their primary target market). Ninety-four percent of the 228 respondents in the newer prototype store were aged between 14 and 40 years and $98 \%$ were female. Ninety-three percent of the 225 respondents in the older prototype store were aged between 14 and 40 years and $98 \%$ were female. The response rate in the newer prototype was $25 \%$, and $30 \%$ in the older prototype. Potential respondents were asked pre-screening questions in advance of their participation in the survey concerning their previous (non)visits to stores of the retailer in question. Groups such as international tourists were excluded from the data collection given their possible higher level of unfamiliarity with the store designs of the retailer.

The sampling of high numbers of females is justified on the basis of their representativeness of an important market for fashion consumption. Both stores are within $200 \mathrm{~m}$ walking distance of one another with very similar consumer groups serviced in both stores. Other research to deliberately survey high proportions of females in retail contexts includes Yoo et al. (1998), Michon et al. (2007). Apparel and accessories stores frequently target female shoppers, and males tend to generate model noise given their different attitudes to fashion, according to Michon et al. (2007), and may contribute to structural and factor loading invariance. These approaches to sampling and survey administration address the demands of Sudman (1980) for careful sampling to also observe eligibility and ties constraints as consumers pass specified

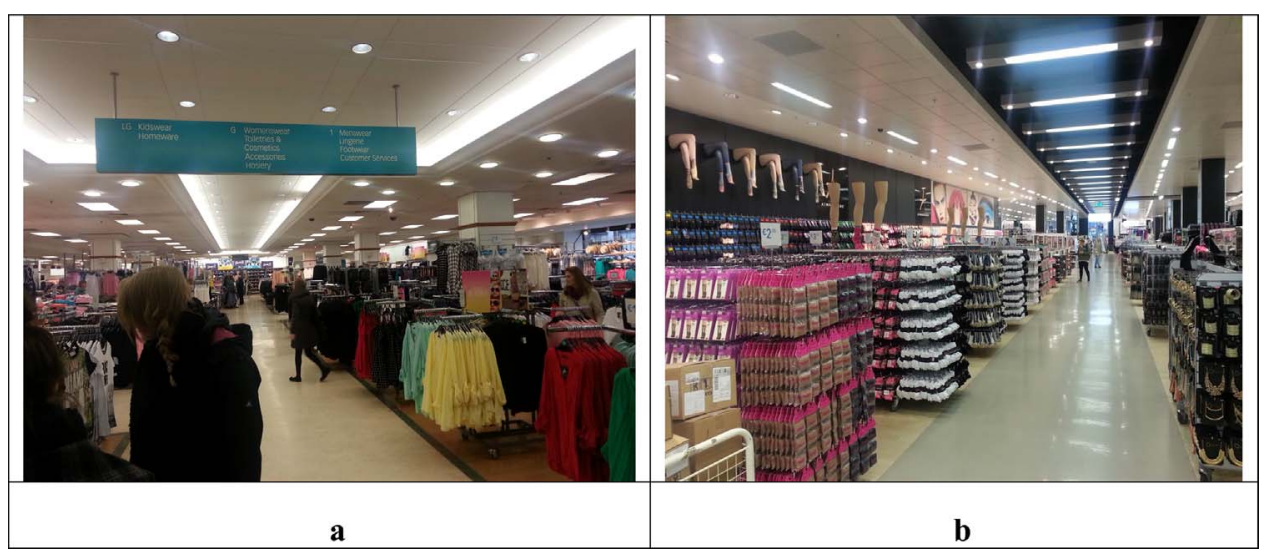

Fig. 2. Images of the two designs: a) the older store layout, signage, fixturing, lighting and color; and b) the newer store layout, signage, fixturing lighting and color. 


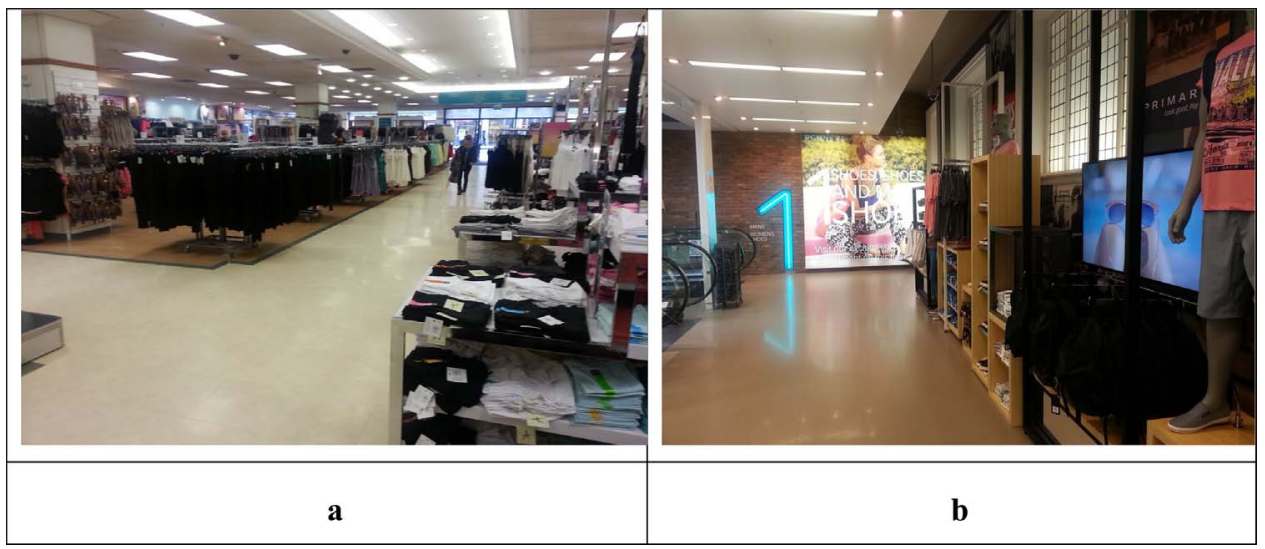

Fig. 3. Images of the two designs: a) the older store layout, signage, fixturing, lighting and color; and b) multi-media screens and materials used in the newer design. locations before they are intercepted to participate in surveys. Minimal confounding effects, such as sales promotions, took place during the survey administration. Consumers were intercepted after they visited the checkout and had thus spent time in the store.

\subsection{Applied scales and measures}

The retail brand loyalty items were drawn from Yoo et al. (2000), Yoo and Donthu (2001), Beristain and Zorrilla (2011), and Beatty and Kahle (1988). The retail price items were drawn from Jara and Cliquet (2012). Store novelty, complexity, and design pleasure were extracted principally from: Cox and Cox (2002), Sherman et al. (1997), Donovan and Rossiter (1982), Kaltcheva and Weitz (2006), and Baker et al. (1994). Familiarity was examined using a measure for the number of other stores in the retailer's network the respondent had visited. Consumers were asked to list the names of the store locations of the retailer they had shopped in, within the preceding six months; these responses were then used to calculate the number of stores the consumers shopped in and were familiar with.

\section{Data analyses and results}

\subsection{Descriptive statistics}

The results confirm that the more established design was perceived to be less novel (M older $5.1 \mathrm{v} \mathrm{M}$ newer 2.8 , SD older $1.3 \mathrm{v}$ SD newer $1.3, \rho / \alpha$ older $.87 / .80 \mathrm{v} \rho / \alpha$ newer $.87 / .81$ ), and more complex (M older 3.6 v M newer 2.6, SD older 1.4 v SD newer $1.1, \rho / \alpha$ older .94/ $.91 \mathrm{v} \rho / \alpha$ newer .93/.89). Consumers evidence a greater design pleasure towards the newer design (M newer $2.5 \mathrm{v}$ M older 4.3, SD newer $1.2 \mathrm{v}$ SD older $1.5, \rho / \alpha$ newer $.88 / .74 \mathrm{v} \rho / \alpha$ older $.91 / .81$ ), but very similar retail brand loyalties (M older $3.0 \mathrm{v} \mathrm{M}$ newer 3.0, SD older $1.5 \mathrm{v}$ SD newer $1.5, \rho / \alpha$ older $.91 / .85 \mathrm{v} \rho / \alpha$ newer $.92 / .87$. These results are provided in Table 1 ; $t$-test comparisons for each of these variables across the two designs similarly confirm significant differences for novelty, complexity, familiarity, and design pleasure are presented in Appendix A.

\subsection{Common method bias}

In our empirical study we utilised data that is based on self-reports. Hence, we considered the issue of common method bias (CMB), which can affect the data and findings (Richardson et al., 2009). We employed both the questionnaire design and latent method factor (LMF) approaches to minimising and evaluating the effects of CMB - see Podsakoff et al. (2012), and Richardson et al. (2009), for a critical discussion of the absence of a common understanding of CMB treatments in the extant literature.

To rule out a possible negative effect of a CMB on our data, we applied a two-step approach. First, we tried to avoid CMB by considering the questionnaire design suggestions of Podsakoff et al. (2003), Podsakoff, MacKenzie and Podsakoff (2012). The research assistants who administered the questionnaire were trained to adapt to the pace of questioning and in guiding respondents from section to section in the questionnaire. In particular, they carefully explained the different scales to the respondents. This helped to address potential respondent fatigue and monotony of questioning issues. In terms of the structure of the research instrument, we clearly separated the questions; those questions related to the dependent constructs were asked prior to those related to the independent ones. We applied a variety of scales throughout the questionnaire (semantic differential, rating scales, and continuous scales). We also did not reveal the specific purpose of our research and assured confidentiality to respondents.

Secondly, we investigated the existence of a CMB in our data using a latent method factor (LMF) test. The latent method factor (LMF) subsumed all indicators under one construct in the model (Podsakoff et al., 2003). We then estimated the model with and without the LMF. A comparison of the results in both samples revealed that neither the factor loadings nor the path coefficients differed substantially in value, and all were significant ( $t$-value $>1.965$ ) and positive. After having tried to prevent the occurrence of a CMB in the first place, and subsequently testing for the presence of a CMB in the two sets of data, we can conclude that common method variance is not a significant issue in our data and thus a CMB is less likely to be evident in our results.

\subsection{Examination of reliability, convergent validity and discriminant validity}

The six constructs indicated good internal consistencies in both samples, with Cronbach alphas $(\alpha)$ above .70 (Fornell and Larcker, 1981; see Table 1). In both samples the constructs' composite reliabilities $(\rho>.60)$ achieved the recommended cut-off criteria (Fornell and Larcker, 1981; see Table 1). To test for measurement validity we calculated a confirmatory factor analysis using the software IBM SPSS Amos Version 20. The data fit the model very well, and all fit measures are beyond the recommended thresholds (see Appendix A). The constructs' discriminant validities, the average variance extracted (AVE), was larger than the highest of the squared inter-correlations with the other factors in the measurement model (Fornell and Larcker, 1981; see Table 1).

\subsection{Measurement invariance}

To identify differences between the measurement models in the two samples, a multi-group-comparison test was performed (Brown, 2006). The aim of this analysis is to determine the existence of significant differences (variances) between the factor loadings of the two groups. By applying a $\chi^{2}$ difference test between the unconstrained model (all 
Table 1

Measures of central tendency, convergent validity, composite reliability and discriminant validity.

\begin{tabular}{|c|c|c|c|c|c|c|c|c|c|}
\hline Latent Constructs & $\mu / \sigma$ & $\rho / \alpha$ & $\xi_{1}$ & $\xi_{2}$ & $\xi_{3}$ & $\xi_{3}$ & $\xi_{3}$ & $\eta_{1}$ & \\
\hline \multicolumn{10}{|c|}{ Older Design } \\
\hline Familiarity $\left(\xi_{1}\right)$ & $2.1 / 1$ & - & $(-)$ & & & & & & \\
\hline Store Novelty $\left(\xi_{2}\right)$ & $5.1 / 1.3$ & $.87 / .80$ & .00 & $(.62)$ & & & & & \\
\hline Store Design Pleasure $\left(\xi_{3}\right)$ & $4.3 / 1.5$ & $.91 / .81$ & .02 & .10 & $(.84)$ & & & & \\
\hline Store Complexity $\left(\xi_{4}\right)$ & $3.6 / 1.4$ & $.94 / .91$ & .01 & .45 & .28 & $(.79)$ & & & \\
\hline Retail Price $\left(\xi_{5}\right)$ & $1.5 / .6$ & $.88 / .84$ & .01 & .00 & .00 & .01 & $(.64)$ & & \\
\hline Retail Brand Loyalty $\left(\eta_{1}\right)$ & $3.0 / 1.5$ & $.91 / .85$ & .02 & .02 & .01 & .08 & .10 & & $(.76)$ \\
\hline \multicolumn{10}{|c|}{ Newer Design } \\
\hline Familiarity $\left(\xi_{1}\right)$ & $2.1 / 1$ & $1 / 1$ & $(-)$ & & & & & & \\
\hline Store Novelty $\left(\xi_{2}\right)$ & $2.8 / 1.3$ & $.87 / .81$ & .03 & $(.64)$ & & & & & \\
\hline Store Design Pleasure $\left(\xi_{3}\right)$ & $2.5 / 1.2$ & $.88 / .74$ & .00 & .09 & $(.79)$ & & & & \\
\hline Store Complexity $\left(\xi_{4}\right)$ & $2.6 / 1.1$ & $.93 / .89$ & .03 & .25 & .19 & $(.76)$ & & & \\
\hline Retail Price $\left(\xi_{5}\right)$ & $1.6 / .8$ & $.90 / .85$ & .02 & .09 & .04 & .10 & $(.69)$ & & \\
\hline Retail Brand Loyalty $\left(\eta_{1}\right)$ & $3.0 / 1.5$ & $.92 / .87$ & .04 & .03 & .05 & .14 & .12 & & $(.79)$ \\
\hline
\end{tabular}

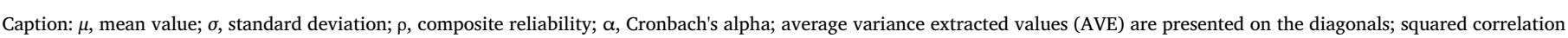
matrix for latent constructs shown below the diagonals.

parameters are allowed to vary freely across the two groups) and the constrained model (an equality constraint on all factor loading is imposed) this test evaluates the null hypotheses that the constrained model is equal to the unconstrained model. Therefore, the differences of $\chi^{2}$-values $\left(\Delta \chi^{2}\right)$ of the two models are used to indicate whether the hypotheses should be accepted. The $\chi^{2}$-difference test turned out to be insignificant $\left(\Delta \chi^{2}, 11.07 ; d f, 12 ; p, .523\right)$. We also went into greater detail and tested for variances between each factor loading. Again, we found insignificant differences (see Appendix A). We thus conclude that the two measurement models are invariant and the factor loadings are not significantly different.

\subsection{Global Fit}

Based on the suggestions of Anderson and Gerbing (1988), Hu and Bentler (1999), we tested the global fit of our model with the two sets of data. In both settings the $\chi^{2}$ values (older design (OD), 232.5 (df, 127), newer design (ND) 229.9 ( $d f, 126)$ are significant. The Root Mean Square Error of Approximation that measures the absolute fit is below the recommended cut-off value of .08 (OD, .06; ND, .06). The TuckerLewis Index (OD, .94; ND, .94) and the Comparative Fit Index (OD, .93; $\mathrm{ND}, .93$ ) - both measuring the incremental fit of the model - are larger than .9 for both stores. Finally, the parsimonious fit measured by the normed $\chi^{2}(\mathrm{CMIN} / d f)$ is below the threshold of 3 (OD, 1.83; ND, 1.81). We thus conclude that the empirical data fit the proposed model to a satisfactory degree.

\subsection{Structural effects}

Table 2 presents the results of the estimations of the structural effects using co-variance structural equation modeling utilizing Amos Version 22.0. In both design settings store novelty positively effects both store complexity $\left(\gamma_{32}\right)$ and store design pleasure $\left(\gamma_{42}\right)$, which leads to the acceptance of hypotheses . Store complexity impacts on store design pleasure $\left(\gamma_{34}\right)$; store design pleasure in-turn effects retail brand loyalty $\left(\gamma_{13}\right)$. We thus confirm . Another significant effect in both settings is identified between retail price and retail brand loyalty $\left(\gamma_{15}\right)$, and consequently $\mathrm{H}_{9}$ is confirmed. No significant association was found between store novelty and retail brand loyalty $\left(\gamma_{12}\right)$ as well as between store complexity and retail brand loyalty $\left(\gamma_{14}\right)$. This leads to the rejection of hypotheses. The results of the hypotheses testing differ between both stores for the effects of familiarity on store novelty $\left(\gamma_{21}\right)$ as well as for the effect of store design pleasure on retail price $\left(\gamma_{53}\right)$. As these effects were only significant in the newer design setting, hypotheses could only be confirmed for the newer design.

\subsection{Multi-group comparison of structural effects}

Furthermore, a multi-group comparison between the two structural models reveals three differences in the coefficient values (see Table 2). This comparison follows the same procedure as presented in the measurement invariance section. We tested for invariance for each effect separately by comparing the constrained model, i.e. the coefficient is restricted to be equal, with the unconstrained model. The $\chi^{2}$-differences reveal three significant differences between effects. The impact of store design pleasure on retail price $\left(\gamma_{53} ; \Delta \chi, 9.3 ; d f, 1\right.$; $\mathrm{p}<.01$ and the impact of familiarity on store novelty $\left(\gamma_{21} ; \Delta \chi, 7.4 ; d f\right.$, $1 ; \mathrm{p}<.01)$ is significant, and much lower in the older design setting. The effect of store novelty on store design pleasure $\left(\gamma_{32} ; \Delta \chi, 4.5 ; d f, 1\right.$; $\mathrm{p}<.05)$ is significant in both settings but significantly lower in the

Table 2

Structural Effects (Standardized Coefficients) and Model Comparisons.

\begin{tabular}{|c|c|c|c|}
\hline Structural Effect (Hypothesis) & Older Design & Newer Design & $\Delta \chi^{2}(\Delta d f=1)$ \\
\hline $\mathrm{H}_{1}\left(\gamma_{21}\right)$ : Familiarity $\left(\xi_{1}\right) \rightarrow$ Store Novelty $\left(\xi_{2}\right)$ & $.09^{\mathrm{ns}}$ & $.20^{*}$ & $7.4^{* * *}$ \\
\hline $\mathrm{H}_{2}\left(\gamma_{32}\right)$ : Store Novelty $\left(\xi_{2}\right) \rightarrow$ Store Design Pleasure $\left(\xi_{3}\right)$ & $.66^{* * * *}$ & $.47^{* * * *}$ & $4.5^{*}$ \\
\hline $\mathrm{H}_{3}\left(\gamma_{42}\right)$ : Store Novelty $\left(\xi_{2}\right) \rightarrow$ Store Complexity $\left(\xi_{4}\right)$ & $.40^{* * *}$ & $.36^{* * *}$ & $.2^{\mathrm{ns}}$ \\
\hline $\mathrm{H}_{4}\left(\gamma_{34}\right)$ : Store Complexity $\left(\xi_{4}\right) \rightarrow$ Store Design Pleasure $\left(\xi_{3}\right)$ & $.32^{* * *}$ & $.33^{* * * *}$ & $.2^{\mathrm{ns}}$ \\
\hline $\mathrm{H}_{5}\left(\gamma_{12}\right)$ : Store Novelty $\left(\xi_{2}\right) \rightarrow$ Retail Brand Loyalty $\left(\eta_{1}\right)$ & $-.20^{\mathrm{ns}}$ & $-.10^{\mathrm{ns}}$ & $.3^{\mathrm{ns}}$ \\
\hline $\mathrm{H}_{6}\left(\gamma_{13}\right)$ : Store Design Pleasure $\left(\xi_{3}\right) \rightarrow$ Retail Brand Loyalty $\left(\eta_{1}\right)$ & $.58^{* *}$ & $.29^{*}$ & $2.0^{\mathrm{ns}}$ \\
\hline $\mathrm{H}_{7}\left(\gamma_{14}\right)$ : Store Complexity $\left(\xi_{4}\right) \rightarrow$ Retail Brand Loyalty $\left(\eta_{1}\right)$ & $-.14^{\mathrm{ns}}$ & $-.11^{\mathrm{ns}}$ & $3.3^{\mathrm{ns}}$ \\
\hline $\mathrm{H}_{8}\left(\gamma_{53}\right)$ : Store Design Pleasure $\left(\xi_{3}\right) \rightarrow$ Retail Price $\left(\xi_{5}\right)$ & $.04^{\mathrm{ns}}$ & $.39^{* * * *}$ & $9.3^{* * *}$ \\
\hline $\mathrm{H}_{9}\left(\gamma_{15}\right)$ : Retail Price $\left(\xi_{5}\right) \rightarrow$ Retail Brand Loyalty $\left(\eta_{1}\right)$ & $.23^{* * *}$ & $.29^{* * * * k}$ & $.3^{\mathrm{ns}}$ \\
\hline
\end{tabular}

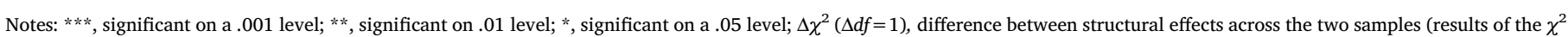
difference test). 
newer design store (consumers in the older store design perceive less novelty and design pleasure).

All the other coefficients were not significantly different from each other $\left(\Delta \chi^{2}<3.50 ; d f, 1 ; \mathrm{p}>.05\right)$. This means that there are few multigroup differences separately for store novelty, design pleasure, complexity and price to the retail brand loyalty association. The absence of a statistical difference in the store design pleasure to retail brand loyalty association across both designs $\left(\gamma_{13} ; \Delta \chi, 2.0 ; d f, 1 ; \mathrm{p}>.05\right)$, in particular, is unexpected. There are different theoretical reasons for how store designs in both the older and newer stores both confer retail brand loyalty gains on the retailer; the discussions section examines why there are few statistical differences in the comparisons of perceptions of both designs.

Significant effects are found for store design pleasure on retail price perception in the newer designed store $(B=.39$; df, $1 ; \mathrm{p}<.001)$, but insignificant effects are correspondingly found for this association for the older designed store ( $\mathrm{B}=.04$; df, $1 ; \mathrm{p}>.05$ ). Multi-group comparisons of the effects of store design pleasure on retail price perception furthermore confirm the presence of different consumer perceptions across both designs $\left(\gamma_{53}, \Delta \chi, 9.3 ; d f, 1 ; \mathrm{p}<.01\right)$, and a potential erosion of the retailer's perceived price competitiveness on account of the newer design introduction. Both the older and newer designs therefore confer loyalty gains for the retailer, but the newer store design presents the retailer with price perception erosion outcomes - a source of potential strategic concern for the retailer.

\subsection{Model robustness test}

The control variables (age, occupation, spending, retention time, design value, product fashionability, product quality and avoidance behaviors) were examined to consider confounding effects on the proposed model in the two samples. The tests for confounding effects on the model, using these control variables, employed a procedure used by Robson et al. (2008). Comparisons of the effect sizes of the structural paths in both samples between models, including and excluding each of the control variables, established that all $\Delta X_{(1)}^{2}$ values were very low («3.841), and insignificant at the .05 level. These results suggest that these control variables do not confound the expected effects in both samples in the conceptual model.

\section{Discussion}

The findings presented in this paper contribute to extant understandings of novel and complex designs and their role in explaining retail brand loyalty across different store prototypes. Critically, when novel store design introductions take place in the context of specific target markets, personal service, pricing and ambient conditions (and the only primary difference present is the novelty and complexity of design across the stores), both the newer and older store designs are both found to help build retailer brand loyalty, when mediated via store design pleasure. However, no retail brand loyalty gains are apparent for the newer store design (this is based on the multi-group differences tests and comparisons of both store designs); the newer store design does not confer additional retail brand loyalty advantages over the older design.

Consumers in both the older and newer prototype designs evidence strong store novelty, complexity, and design pleasure associations, and indirect effects on retail brand loyalty, but do so for different theoretical reasons. Consumers in the older design evidence store design pleasure owing to their preference for the familiarity afforded them by the older design. This confirms the preference for the low novelty, low complexity design of the older design where subjective feelings of familiarity associated with higher objective knowledge of the stimulus capture consumers' attention and affect (Kumar and Garg, 2010; Martindale, 1984). The objective and subjective relating of self to design could also help to explain why the hypotheses concerning direct novelty and complexity associations to retail brand loyalty were rejected in the analyses.

Consumers in the newer prototype design, in contrast, welcome the introduction of store novelty and acknowledge this in their design pleasure for the newer design (this is confirmed in significant statistical differences present in the store novelty and design pleasure multi-group comparison tests of structural effects). Consumers may therefore perceive novelty and evidence design pleasure in response to the unusual and innovative character of the design (Veryzer and Hutchinson, 1998). The research findings thus suggest that perceptual fluency effects (Reber, Winkielman and Schwarz, 1998; Reber, Schwarz and Winkielman, 2004; Winkielman et al., 2006) can take place in both newer and older design contexts. Consumers are attracted by novel design and processing novel design proves satisfying and pleasurable in itself. However, consumers also draw comfort from the familiar, and in low novelty contexts, the presence of perceptual fluency effects. Consumers in lower store novelty contexts possess the ability to more easily reconcile incoming stimulus information to their existing knowledge structures (Kumar and Garg, 2010; Martindale, 1984).

Notably, consumers in the newer design store also appear to be more familiar with the other store designs of the retailer. Although consumers experience design pleasure in different ways, the confirmation of significant multi-group differences in the familiarity-novelty association, also suggests that consumers of newer designs can also be attracted by and experience pleasure towards familiar designs, and not only new and unfamiliar designs. These findings therefore confirm the complex nature of how novel information is reconciled to prior design knowledge and branding perceptions.

The results of this cross-sectional research confirm that competitiveness benefits for businesses can be promoted by appropriate store novelty introductions. Store novelty promotes retail brand loyalty when it is mediated by store design pleasure. However, the novelty introductions also have the effect of influencing price perceptions in the newer designed store. Multiple-group, cross-sectional comparisons confirm significant differences in the store design pleasure and retail price perceptions between the newer and older prototype designs, but few retail brand loyalty differences. This underscores future potential negative repositioning issues for fast-fashion retailers that compete strongly on price: new store prototype designs can encourage consumers to perceive that prices have risen in novelty introduction contexts even if the retailer does not charge different prices across its store network.

\section{Managerial implications, limitations and future research}

\subsection{Managerial implications}

This research examines novel design introductions in a fast-fashion retailer who has traditionally employed a mono-prototype strategy. Consumers traditionally have demonstrated strong brand loyalty to the retailer under investigation. However, important competitive questions of securing differentiation through improved customer experiences, involving a change to a multi-prototype strategy, currently constitutes a key strategic concern for the retailer. The findings suggest that designers and brand managers should carefully manage store novelty introductions as consumers' perceptions of price competiveness erosion could result. Consideration should be given to the functional nature of their designs and appropriateness for given target markets. Missiondriven consumers used to strongly established prototype designs when confronted with novel designs, with incorporations of newer materials and audio-visual elements, for instance, may not identify as easily with these changed designs as consumers who welcome immersive, engaging experiences. Any weakening of retail brand loyalty arising from perceptions of price competitiveness erosion, due to inappropriate store introductions, would be an obvious concern to retailers in many different sectors. 


\subsection{Limitations and future research}

This research involves a limited, cross-sectional study of two store designs of the same retailer. Further research is necessary to ensure the generalizability of these findings from a fast-fashion context to other retail sectors and contexts. Future research could possibly extend this research to develop proof-of-concepting tools that could better aid retailers in their understanding of the communicative effects of store design on consumers. More research is required, however, to identify how consumers perceive novel and complex designs. Most retailers tend to introduce deliberate, novel designs that relate to previous designs, as is the case in this research. However, it is unknown if these same perceptual fluency effects take place in extreme store novelty introductions contexts where subsequent prototype designs bear little or no similarity to their predecessors.

\section{Conclusions}

The findings of this paper suggest how consumers may assimilate the novelty and complexity content in newer store prototype designs. Moreover, consumers of newer store prototype designs exhibit a heightened sensitivity to price perceptions with potentially negative retail brand loyalty implications. This paper contributes to the extant store environment literature by underscoring the need to examine the effects of novelty and complexity, in consumers' perceptions of store prototype designs, and identifies, together in conjunction with price perception, their role in influencing retail brand loyalty.

Appendix A. Measurement Items

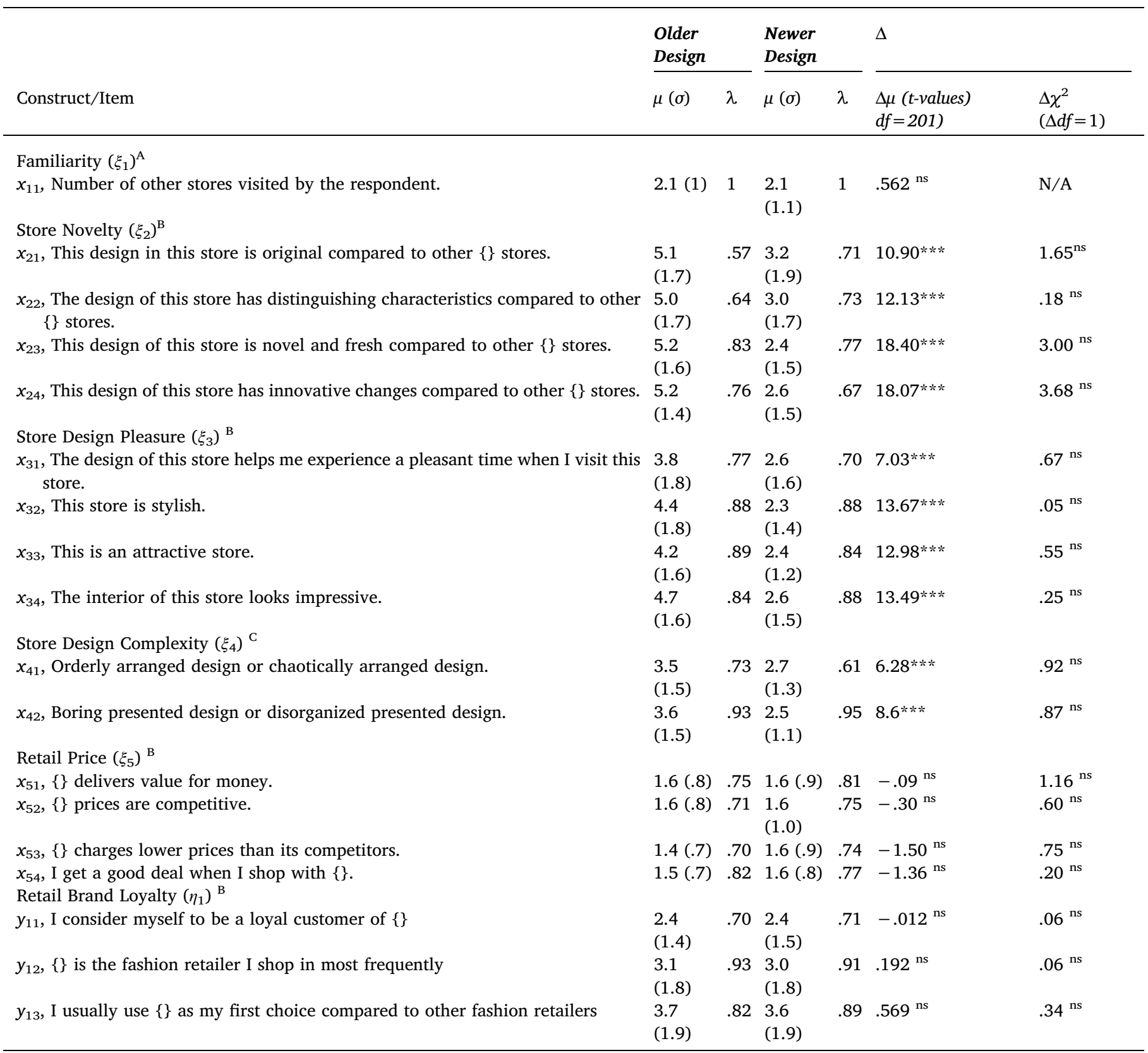

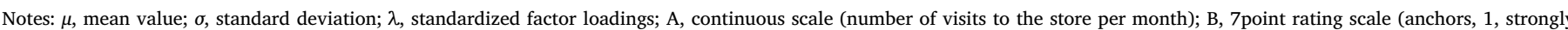

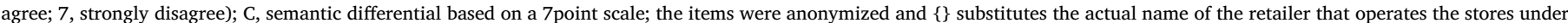

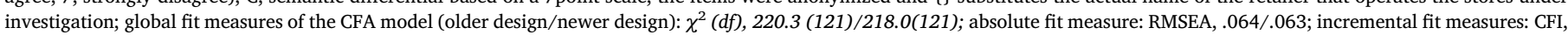




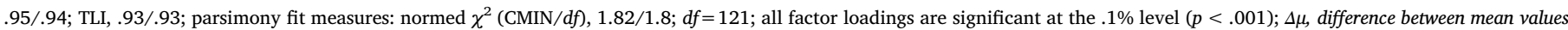

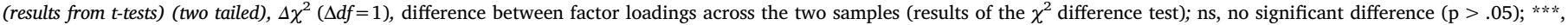
significant difference $(\mathrm{p}<.001)$;

\section{References}

Anderson, J., Gerbing, D., 1988. Structural equation modeling in practice: a review and recommended two-step approach. Psychol. Bull. 103 (3), 411-423.

Baker, J., Grewal, D., Parasuraman, A., 1994. The influence of store environment on quality inferences and store image. J. Acad. Mark. Sci. 22 (4), 328-339.

Baker, J., Parasuraman, A., Grewal, D., Voss, G., 2002. The influence of multiple store environment cues on perceived merchandise value and patronage intentions. J. Mark. 66 (April), 120-141.

Beatty, L., Kahle, S., 1988. Alternative hierarchies of the attitude-behaviour relationship: the impact of brand commitment and habit. J. Acad. Mark. Sci. 16 (2), 1-10.

Beristain, J., Zorrilla, P., 2011. The relationship between store image and store brand equity: a conceptual framework and evidence from hypermarkets. J. Retail. Consum. Serv. 18, 562-574.

Berlyne, D., 1971. Aesthetics and Psychobiology. Appleton-Meredith Corporation, New York.

Biederman, I., Vessel, E., 2006. Perceptual pleasure and the brain. Am. Sci. 94 (MayJune), 249-255.

Bloch, P., 1995. Seeking the ideal form: product design and consumer response. J. Mark. 59 (July), 16-29.

Bloch, P., Brunel, F., Arnold, T., 2003. Individual differences in the centrality of visual product aesthetics: concept and measurement. J. Consum. Res. 29 (March), 559-565.

Brown, T., 2006. Confirmatory Factor Analysis for Applied Research. Guilford Press, London.

Bruggen, E., Foubert, B., Gremler, D., 2011. Extreme makeover: short and long-term effects of a remodeled servicescape. J. Mark. 75 (5), 71-87.

Cohen, J., Basu, K., 1987. Alternative models of Categorisation: toward a contingent processing framework. J. Consum. Res. 13 (March), 455-472.

Cox, D., Cox, A., 2002. Beyond first impressions: the effects of repeated exposure on consumer liking of visually complex and simple product designs. J. Acad. Mark. Sci. 30 (2), 119-130.

Day, G., 1969. A two-dimensional concept of brand loyalty. J. Advert. Res. 9 (September), $29-35$.

Dick, A., Basu, K., 1994. Customer loyalty: toward an integrated conceptual framework. J. Acad. Mark. Sci. 22 (2), 99-113.

Dodds, W., Monroe, K., Grewal, D., 1991. Effects of price, brand, and store information on Buyers' product evaluations. J. Mark. Res. 28 (August), 307-319.

Dolbec, P.-Y., Chebat, J.-C., 2013. The Impact of a Flagship Vs. A Brand Store on Brand Attitude, Brand Attachment and Brand Equity. J. Retail. 89 (4), 460-466.

Donovan, R., Rossiter, J., 1982. Store atmosphere: an environmental psychology approach. J. Retail. 58 (1), 34-57.

Duarte, B., Morais, D., Dorsch, M., Backman, J., 2004. Can tourism providers Buy their Customers' loyalty? Examining the influence of customer-Provider investments on loyalty. J. Travel Res. 42 (3), 235-243.

Elliot, A., Eder, A., Harmon-Jones, E., 2013. Approach-avoidance motivation and Emotion: Convergence and divergence. Emot. Rev. 5 (3), 308-311.

Eroglu, S., Machleit, K., 2008. Theory in Consumer-Environment Research: diagnosis and Prognosis. In: Haugtvedt, C., Herr, P., Kardes, F. (Eds.), Handbook of Consumer Psychology. Psychology Press, New York.

Fornell, C., Larcker, D., 1981. Evaluating structural equations models with unobserved variables and measurement error. J. Mark. Res. 18 (1), 39-50.

Foster, J., McLelland, M., 2015. Retail atmospherics: the impact of a brand dictated theme. J. Retail. Consum. Serv. 22, 195-205.

Frith, C., Nias, D., 1974. What determines aesthetic preferences? J. General. Psychol. 91, 163-173.

Garaus, M., Wagner, U., Kummer, C., 2015. Cognitive fit, retail shopper confusion, and shopping value: empirical investigation. J. Bus. Res. 68, 1003-1011.

Hansen, R., Deutscher, T., 1977. An empirical investigation of attribute importance in retail store selection. J. Retail. 53 (4), 59-95.

Hekkert, P., Leder, H., 2008. Product Aesthetics. In: Schifferstein, H., Hekkert, P. (Eds.), Product Experience. Elsevier, London \& Amsterdam, pp. 259-285.

Hekkert, P., van Wieringen, P., 1990. Complexity and prototypicality as determinants of the appraisal of cubist paintings. Br. J. Psychol. 81, 483-495.

Herr, P., 1989. Priming price: prior knowledge and context effects. J. Consum. Res. 16 (June), 67-75.

Hirschman, E., 1980. Innovativeness, novelty seeking, and consumer creativity. J. Consum. Res. 7 (December), 283-295.

Holbrook, M., 1980. Some preliminary notes on research in consumer esthetics. Adv. Consum. Res. 104-108.

Hollenbeck, C., Peters, C., Zinkhan, G., 2008. Retail spectacles and brand meaning: insights from a brand museum case study. J. Retail. 84 (3), 334-353.

Hu, L., Bentler, P., 1999. Cutoff criteria for fit indexes in covariance structure analysis: conventional criteria versus new alternatives. Structural Equ. Model.: a Multidiscip. J. 6 (1), 1-55.

Jacoby, J., Chestnut, R., 1978. Brand Loyalty: Measurement and Management. Wiley, New York.

Jara, M., Cliquet, G., 2012. Retail brand equity: conceptualisation and measurement. J. Retail. Consum. Serv. 140-149.

Jinfeng, W., Zhilong, T., 2009. The impact of selected store image dimensions on retailer equity: evidence from 10 Chinese hypermarkets. J. Retail. Consum. Serv. 16, 486-494.

Joy, A., Wang, J.-J., Chan, T.-S., Sherry, J., Cui, G., 2014. M(Art) Worlds: consumer perceptions of how luxury brand stores become art institutions. J. Retail. 90 (3), 347-364.

Kaltcheva, V., Weitz, B., 2006. When should a retailer create an exciting store environment? J. Mark. 70 (January), 107-118.

Kozinets, R., 2002. Themed Flagship brand stores in the new Millennium: theory, practice, prospects. (and al., e) J. Retail. 78, 17-29.

Kumar, A., Kim, Y.-K., 2014. The store-as-a-brand strategy: the effect of store environment on customer responses. J. Retail. Consum. Serv. 21, 685-695.

Kumar, M., Garg, N., 2010. Aesthetic principles and cognitive emotion appraisals: how much of the beauty lies in the eye of the beholder? J. Consum. Psychol. 20, 485-494.

Landwehr, J., McGill, A., Herrmann, A., 2011. It's got the look: the effect of friendly and aggressive "facial" expressions on product liking and sales. J. Mark. 75 (3), 132-146.

Landwehr, J., Wentzel, A., Herrmann, A., 2012. The tipping point of design: how product design and brands interact to affect consumers' preferences. Psychol. Mark. 29 (6), $422-433$.

Lee, A., Labroo, A., 2004. The effect of conceptual and perceptual fluency on brand evaluation. J. Mark. Res. 61 (May), 151-165.

Littel, S., Orth, U., 2013. Effects of package visuals and haptics on brand evaluations. Eur. J. Mark. 47 (1/2), 198-217.

Loken, B., Ward, J., 1990. Alternative approaches to understanding the determinants of typicality. J. Consum. Res. 17 (September), 111-126.

Londono, J., Elms, J., Davies, K., 2016. Conceptualising and measuring consumer-based brand-retail-channel equity. J. Retail. Consum. Serv. 29 (March), 70-81.

Martindale, C., 1984. The pleasures of thought: a theory of cognitive Hedonics. J. Mind Behav. 5 (1), 49-80.

Martindale, C., Moore, K., 1988. Priming, prototypicality, and preference. J. Exp. Psychol.: Human. Percept. Perform. 14 (4), 661-670.

Mehrabian, A., Russell, J., 1974. An Approach to Environmental Psychology. MIT Press, Cambridge.

Meyers-Levy, J., Tybout, A., 1989. Schema congruity as a basis for product evaluation. J. Consum. Res. 16 (June), 39-54.

Michon, R., et al., 2007. The shopping experience of female Fashion leaders. Int. J. Retail Distrib. Manag. 35 (6), 488-501.

Oh, J., Fiorito, S., Cho, H., Hofacker, C., 2008. Effects of design factors on store image and expectation on merchandise quality in web-based stores. J. Retail. Consum. Serv. 15, 237-249.

Oliver, R., 2014. Satisfaction: A Behavioral Perspective on the Consumer, ME Sharpe, London.

Oliver, R., 1980. A cognitive model of the antecedents and consequences of satisfaction decisions. J. Mark. Res. 17 (November), 460-469.

Oliver, R., 1997. Satisfaction: A Behavioural Perspective on the Consumer. McGraw-Hill, New York.

Oliver, R., Winer, R., 1987. A Framework for the Formation and Structure of Consumer Expectations: review and Propositions. J. Econ. Psychol. 8 (4), 469-499.

Pan, Y., Zinkhan, G.M., 2006. Determinants of retail patronage: a meta-analytical perspective. J. Retail. 82, 229-243.

Pappu, R., Quester, P., 2016. How does brand innovativeness affect brand loyalty? Eur. J. Mark. 50 (1/2), 2-28.

Park, C., Eisingerich, A., Park, J., 2013. Attachment-aversion model of consumer-brand relationships. J. Consum. Psychol. 23 (2), 229-248.

Podsakoff, P., et al., 2003. Common method biases in behavioral research: a critical review of the literature and recommended remedies. J. Appl. Psychol. 88, 879-903.

Podsakoff, P.M., MacKenzie, S.B., Podsakoff, N.P., 2012. Sources of method bias in social science research and recommendations on how to control it. Annu. Rev. Psychol. 63, 539-569.

Ponsonby-McCabe, S., Boyle, E., 2006. Understanding brands as experiential spaces: axiological implications for marketing strategists. J. Strateg. Mark. 14, 175-189.

Reber, R., Schwarz, N., Winkielman, P., 2004. Processing fluency and aesthetic pleasure: is beauty in the Perceiver's processing experience. Personal. Social. Psychol. Rev. 8 (4), 364-382.

Reber, R., Winkielman, P., Schwarz, N., 1998. Effects of perceptual fluency on affective judgments. Psychol. Sci. 9 (1), 45-48.

Reutterer, T., Teller, C., 2009. Store format choice and shopping trip types. Int. J. Retail Distrib. Manag. 37, 695-710.

Robson, M., Katsikeas, C., Bello, D., 2008. Drivers and performance outcomes of Trust in International Strategic alliances: the role of organisational complexity. Organ. Sci. 19, 647-665.

Richardson, H., Simmering, M., Sturman, M., 2009. A tale of three perspectives: examining post hoc statistical techniques for detection and corrections of common method variance. Organ. Res. Methods 12 (4), 762-800.

Sharma, A., Stafford, T., 2000. The effects of retail atmospherics on customers' perceptions of salespeople and customer persuasion: an empirical investigation. J. Bus. Res. 49, 183-191.

Sherman, E., Multhur, A., Smith, R., 1997. Store environment and consumer purchase behavior: mediating role of consumer emotions. Psychol. Mark. 14 (4), 361-378.

Snelders, D., Hekkert, P., 1999. Association measures as Predictors of product originality. Adv. Consum. Res. 26, 588-592. 
Stocchi, L., Wright, M., Driesener, C., 2016. Why familiar brands are sometimes harder to remember. Eur. J. Mark. 50 (3/4), 621-638.

Sudman, S., 1980. Improving the quality of shopping centre sampling. J. Mark. Res. 17 (4), 423-431.

Sujan, M., 1985. Consumer knowledge: effects on evaluation strategies mediating consumer judgments. J. Consum. Res. 12 (June), 31-46.

Sujan, M., Dekleva, C., 1987. Product categorisation and inference making: some implications for comparative advertising. J. Consum. Res. 14 (3), 372-378.

Swoboda, B., et al., 2013. the importance of retail brand equity and store accessibility for store loyalty in local competition. J. Retail. Consum. Serv. 20 (3), 251-262.

Teller, C., Dennis, C., 2012. The Effect of ambient scent on consumers'perception, emotions and behaviour - a critical review. J. Mark. Manag. 28 (1/2), 14-36.

van Kenhove, P., de Wulf, K., van Waterschoot, W., 1999. The impact of task definition on store-attribute saliences and store choice. J. Retail. 75 (1), 125-137.

Veryzer, R., Hutchinson, J., 1998. The influence of unity and prototypicality on aesthetic response to new product designs. J. Consum. Res. 24, 374-394.

Wakefield, K., Baker, J., 1998. Excitement at the mall: determinants and effects on shopping response. J. Retail. 74 (4), 515-539.

Walsh, G., Evanschitzky, H., Wunderlich, M., 2008. Identification and Analysis of Moderator Variables: Investigating the Customer-Satisfaction Loyalty Link.

Winkielman, P., Halberstadt, J., Fazendeiro, T., Catty, S., 2006. Prototypes are attractive because they are easy on the mind. Psychol. Sci. 17 (9), 799-806.

Yi, Y., La, S., 2004. What influences the relationship between customer satisfaction and repurchase intention? Investigating the effects of adjusted expectations and customer loyalty. Psychol. Mark. 21 (5), 351-373.

Yoo, B., Donthu, N., 2001. Developing and validating a multidimensional consumer-based brand equity scale. J. Bus. Res. 52, 1-14.

Yoo, B., Donthu, N., Lee, S., 2000. An examination of selected marketing mix elements and brand equity. J. Acad. Mark. Sci. 28 (2), 195-211.

Yoo, C., Park, J., MacInnis, D., 1998. Effects of store characteristics and in-store emotional experiences on store attitude. J. Bus. Res. 42, 253-263.

Zeithaml, V., 1988. Consumer perceptions of price, quality and value: aa means-end model and synthesis of evidence. J. Mark. 52 (July), 2-22. 